\title{
A Proteção da Propriedade Intelectual como Questão de Saúde Pública — o Caso dos Medicamentos e Cosméticos
}

THE PROTECTION OF THE COPYRIGHT AS QUESTION OF PUBLIC HEALTH - THE CASE OF MEDICINES AND COSMETICS

Patrícia Luciane de Carvalho ${ }^{(*)}$

\section{RESUMO}

O presente artigo expõe a ampla tutela jurídica do Direito da Propriedade Intelectual sobre os medicamentos e os cosméticos. Demonstra-se que, em que pese esta proteção transparecer, em um primeiro momento, temática direcionada aos interesses da iniciativa privada, comprova-se a sua relevância também à esfera pública, uma vez que alcança diretamente a saúde pública sobre o aspecto da acessibilidade da saúde, quando esta depende do fornecimento ou aquisição de medicamentos; e, da mesma forma, pode atingir, por isto, indiretamente, a saúde pública através do uso, interno ou externo, de produtos que possam afetar a saúde coletiva, como no caso dos medicamentos e cosméticos.

\section{Palavras-chave}

Cosméticos; Medicamentos; Propriedade Intelectual; Saúde.

(*) Graduada em Direito pela Pontifícia Universidade Católica do Paraná (PUC-PR); especialista em Direito Internacional Tributário pela Faculdade de Direito de Curitiba; MBA em Administração de Empresas e Negócios pela Fundação Getúlio Vargas; mestre em Direito pela PUC-PR; integrante da Associação Portuguesa de Direito Intelectual, da Associação Brasileira de Propriedade Intelectual e membro consultora da Comissão da Propriedade Imaterial da OAB/SP. E-mail: $<$ plcarvalho@yahoo.com.br>.

Recebido em 01.04.10. Aprovado em 15.04.10. 


\section{ABSTRACT}

This article approaches the legal protection of the intellectual property law on medicines and cosmetics. It shows that although this protection appears, at first, directed to the interests of the private enterprise, its relevance to the public sphere is confirmed, since it involves directly the public health on the aspect of health acessibility, when this depends on supplier or acquisition. And, similarly, this could reach, at this time indirectly, the public health through internal or external use of products that can affect health, as in the case of drugs and cosmetics.

\section{Keywords}

Cosmetics; Drugs; Health; Intelectual Property.

\section{INTRODUÇÃO}

A ordem jurídica nacional e os principais tratados internacionais oferecem proteção diversificada aos medicamentos e aos cosméticos. Proteção representada pelo Direito Autoral, Direito das Marcas, do Desenho Industrial, das Patentes, do Software e da Livre Concorrência, todos espécimes do Direito da Propriedade Intelectual.

Tem-se este arcabouço protetivo para, primeiro, proteger os direitos dos pesquisadores, desenvolvedores, produtores e comerciantes de medicamentos ou cosméticos; segundo, para incentivar estes mesmos a permanecerem nestas atividades, uma vez que são eles, predominantemente, e não o Estado, que desenvolvem produtos fármacos à sociedade; e, terceiro, como forma de se efetivar a acessibilidade de medicamentos através de novos medicamentos.

Esta sistemática tem por origem os trabalhos dos atores internacionais, com destaque para a Convenção da União de Paris para a Proteção da Propriedade Industrial de 1883 e para a Convenção de Berna para a Proteção das Obras Literárias e Artísticas de 1886; posteriormente, os trabalhos da Organização Mundial do Comércio através do TRIPS - Acordo Relativo aos Aspectos do Direito da Propriedade Intelectual Relacionados com o Comércio. Especificamente, em relação à saúde pública, têm-se os trabalhos da Organização das Nações Unidas, por meio da Organização Mundial da Saúde e da Organização Mundial da Propriedade Intelectual.

Os diversos países signatários destas convenções absorveram a construção da ordem internacional em suas molduras jurídicas, por isto, em 
certa medida, há compatibilidade do tratamento oferecido ao tema da Propriedade Intelectual e da Saúde, com maior razão ao Direito Autoral, ao das Marcas, do Desenho Industrial, ao das Patentes, ao do Software, ao da Livre Concorrência e ao do acesso a medicamentos.

Faz-se importante a compatibilização em virtude do comércio além fronteiras - consequência da globalização da economia e do comércio virtual - eis que os empresários precisam de uma mínima segurança jurídica de que os seus Direitos da Propriedade Intelectual serão respeitados pelos diversos países, no sentido de que a "criatividade" e a "inovação", depositadas em um medicamento ou em um cosmético, não serão usurpadas por terceiros, promovendo o desvio de clientela em razão da confusão do consumidor. Por sua vez, a população fica à mercê da sistemática de serem os medicamentos e cosméticos produzidos em países desenvolvidos ou por laboratórios multinacionais, o que estabelece ainda mais a dependência por preços e setores de pesquisa distantes da real necessidade de populações de países em desenvolvimento ou de menor desenvolvimento relativo. Por isto tudo, a necessidade de políticas comunitárias.

Medicamentos e cosméticos exteriorizam e promovem um rico conjunto de informações e funcionalidades, desta forma, faz-se necessária a ampla tutela jurídica, desde a formulação até as embalagens e acondicionamentos, eis que desta forma, incentiva-se o desenvolvimento e a comercialização desses produtos, os quais satisfazem a saúde e a estética, mas também a preservação da vida com dignidade. Veja-se o exemplo do protetor solar, que, a depender do país, classifica-se como medicamento ou cosmético. Independente da classificação que receba, é produto essencial para a prevenção do câncer de pele, deste modo, não se pode afastá-lo da importância para a saúde pública, em que pese a possiblidade de ser considerado produto da cosmiatria.

Outro aspecto a observar é que esta proteção deve ser efetiva, eis que a iniciativa privada constantemente deve ser motivada à pesquisa e à comercialização desses produtos, diante da constatação de que a maioria dos países não possui capacidade estatal para substituir os agentes privados na "acessibilidade" a produtos de origem fármaca ou cosmiátrica. A relação, portanto, entre as esferas pública e privada deve ser de complementariedade, no sentido de se tutelar a criatividade e a inovação da esfera produtiva através da promoção e do respeitado aos Direitos da Propriedade Intelectual, uma vez que certo é que estes direitos promovem, além da lucratividade, também a acessibilidade.

\section{CARACTERIZAÇÃO DO MEDICAMENTO E DO COSMÉTICO}

Medicamentos e cosméticos diferenciam-se sob o aspecto dos primeiros voltarem-se, necessariamente, à promoção da saúde física e/ou mental, na 
sua forma preventiva e incidental; são imprescindíveis, diante do competente diagnóstico, à manutenção da vida com dignidade, ou seja, aquela que satisfaça ao pleno desenvolvimento individual e social; relacionam-se as pesquisas e desenvolvimentos das ciências exatas, destacadamente da farmacologia, biologia e genética; e, em razão do vínculo direto com a saúde, necessário, para fins de comercialização, que obtenha licença da Agência Nacional da Vigilância Sanitária - ANVISA.

Por sua vez, os cosméticos em que pesem guardarem estreita identificação com os medicamentos, oriundam-se da cosmiatria, que depende, por certo, das mesmas ciências exatas, contudo, buscam a satisfação estética, a qual não se faz necessária à saúde e ou à vida, ou seja, pode-se viver e sobreviver sem a utilização de cosméticos. De qualquer forma, são aplicados sob o corpo humano, assim podem provocar efeitos sobre a saúde, por esta razão, também devem ser avaliados pela ANVISA.

A Lei n. 5.991 de 17 de Dezembro de 1973, que dispõe sobre o Controle Sanitário do Comércio de Drogas, Medicamentos, Insumos Farmacêuticos e Correlatos, conceitua o que seja medicamento como produto farmacêutico, tecnicamente obtido ou elaborado, com finalidade profilática, curativa, paliativa ou para fins de diagnóstico.

De outro lado, o Decreto n. 79.094 de 05 de Janeiro de 1977, que submete ao sistema da vigilância sanitária os medicamentos, os insumos farmacêuticos, drogas, correlatos, cosméticos, produtos de higiene, saneantes e outros, conceitua cosmético como o de uso externo, destinado à proteção ou ao embelezamento das diferentes partes do corpo, tais como pós faciais, talcos, cremes de beleza, cremes para as mãos e similiares, máscaras faciais, loções de beleza, soluções leitosas, cremosas e adstringentes, loção para as mãos, bases de maquiagem e óleos cosméticos, rouges, blushes, batons, lápis labiais, preparados anti-solares, bronzeadores e simulatórios, rímeis, sombras, delineadores, tinturas capilares, agentes clareadores de cabelo, fixadores, laquês, brilhantinas e similares, tônicos capilares, depilatórios ou epilatórios, preparados para unhas e outros.

Atente-se ao fato de que essa lista é de natureza enumerativa e não taxativa. Desta forma, qualquer outro que se insira na essência do conceito classifica-se como cosmético. Diferentemente não poderia ser, eis que o intenso e progressivo desenvolvimento tecnológico propiciam constantemente novas aplicações e novos produtos. E mais, o Decreto fala em produtos voltados à proteção, ou seja, percebe-se que os cosméticos, em que pese sua normal destinação, importantes são também para a preservação da vida com dignidade.

De resto, medicamentos e cosméticos passam pela fase de pesquisa, desenvolvimento, abordagem da química, da farmacologia e outras ciências exatas. A identificação entre os produtos é tão estreita, com maior razão no 
processo de desenvolvimento e produção, que muitas empresas possuem as duas linhas de produção - medicamentos e cosméticos. $\mathrm{E}$, diante da necessidade de se obter a proteção devida à criatividade e à inovação empregadas, socorrem-se da proteção dos Direitos da Propriedade Intelectual, principalmente, da oferecida pelo Instituto Nacional da Propriedade Industrial — INPI, na concessão de patente sobre formulação.

Dentre as espécies dos Direitos da Propriedade Intelectual, os medicamentos e os cosméticos, de uma forma identificável, podem ser tutelados pelo Direito Autoral e pelo Direito Industrial, este subdividido em Marcas, Desenho Industrial e Patente. Todos com possíveis repercussões no Direito de Software e na Livre Concorrência.

\section{O DIREITO AUTORAL E O DIREITO À INFORMAÇÃO SUFICIENTEMENTE CLARA AO PACIENTE OU CONSUMIDOR}

O Direito Autoral protege, por meio da Lei n. 9.610 de 19 de Fevereiro de 1998, as criações do espírito, expressas por qualquer meio ou fixadas em qualquer tipo de suporte, seja tangível ou intangível, conhecido ou que se invente no futuro. Ou seja, necessário que "a criação" seja exteriorizada para que se vincule com a pessoa física ou jurídica. Não há a necessidade de registrar, mas tão apenas exteriorizar para estabelecer o vínculo com o respectivo titular. Existindo o interesse pelo registro, poder-se-à fazê-lo na Fundação Biblioteca Nacional, com sede no Rio de Janeiro, que funciona como Escritório de Direitos Autorais, ou nos demais escritórios distribuídos pelo Brasil.

Os medicamentos e cosméticos, por uma questão mercadológica e de custo financeiro, necessitam informar aos consumidores e ou pacientes, de modo claro e objetivo (artigo 6을, inciso III, da Lei n. 8.078, de 11 de Setembro de 1990 - a informação adequada e clara sobre os diferentes produtos e serviços, com especificação correta de quantidade, características, composição, qualidade e preço, bem como sobre os riscos que apresentem), elementos essenciais sobre o referido produto, como indicação, contraindicação, posologia, modo de uso e composição. Tudo isto em embalagens práticas, ou seja, pequenas e fáceis de manusear. Assim, não resta muito espaço, uma vez que, além desses elementos, têm-se os voltados à atração do consumidor, como forma e sinais de identificação. Deste modo, não se faz presente, regra geral, criações do espírito em embalagens de medicamentos e de cosméticos. Em existindo estas criações, diante da exteriorização do criador, não podem ser utilizadas por terceiros para a divulgação de produtos identificáveis ou da mesma classe.

Outra situação interna à embalagem é a bula. É neste instrumento que se reúne os elementos obrigatórios e necessários já mencionados que, de 
modo geral, descrevem a aplicação do medicamento e do cosmético, prestam-se a informar. Corresponde à reunião de informações, de caracter científico, as quais destinam-se ao consumidor, farmacêutico e médico e, por uma questão mercadológica, devem ser concisas e suficientemente claras ao homem de conhecimento médio (paciente ou consumidor). Assim, dificilmente representarão, também, criação do espírito. Não se afasta a possibilidade, desde que se supere a transmissão de informações com mero carácter científico.

A Resolução-RDC n. 47, de 08 de Setembro de 2009, estabelece regras para a elaboração, harmonização, atualização, publicação e disponibilização de bulas de medicamentos para pacientes e para profissionais de saúde:

Art. 4ำ Para efeito deste Regulamento Técnico são adotadas as seguintes definições:

(...)

II - bula: documento legal sanitário que contém informações técnico-científicas e orientadoras sobre os medicamentos para o seu uso racional; (grifos do autor)

Decisão do Supremo Tribunal Federal, em Recurso Extraordinário sob n. 88705/RJ, julgada em 24 de Maio de 1979, que, em que pese a anterioridade à Lei de Direitos Autorais n. 9.610, ilustra o entendimento ainda atual:

\section{EMENTA}

"BULA DE REMEDIOS. RECONHECIDA A SUA NATUREZA CIENTÍFICA, POIS DESTINADA A CLASSE MÉDICA E FARMACÊUTICA E FISCALIZADA PELAS AUTORIDADES COMPETENTES, LEGITIMA-SE A SIMPLES REFERÊNCIA OU CITAÇÃO DE UMA PESQUISA CIENTÍFICA SEM OFENSA AO DIREITO DO AUTOR, FACE AO CÓDIGO CIVIL E A LEI ESPECIAL. APLICAÇÃO DOS ARTS. 666, I, DO C. CIVIL E ART. 49, I E III, DA LEI 5988, DE 14.02.75, E NÃO INCIDENCIA, NA ESPÉCIE, DO ART. 25, IV. DA MESMA LEI. NOS TRABALHOS CIENTÍFICOS O DIREITO AUTORAL PROTEGE A FORMA DE EXPRESSÃO, E NÃO AS CONCLUSÕES CIENTÍFICAS OU SEUS ENSINAMENTOS, QUE PERTENCEM A TODOS, NO INTERESSE DO BEM COMUM. AÇÃO PROIBITÓRIA CUJOS RESULTADOS JÁ TINHAM SIDO ALCANCADOS PELA NOTIFICAÇÃO PRÉVIA. RECONHECIDO E PROVIDO PARA JULGAR IMPROCEDENTE A AÇÃO PROIBITÓRIA." (grifos do autor)

O diferencial das informações constantes, interna e externamente, no conjunto informativo e identificador dos medicamentos e cosméticos com as de outros meios é que não representa, por tendência de mercado, criação do espírito, mas sim exteriorização de informação científica. Pode ser que esta 
esteja devidamente protegida pelo Direito das Patentes, mas não alcançará, regra geral, a proteção Autoral. Mesmo porque, são utilizadas embalagens compactas, nas quais prevalece o interesse maior pela clareza de informação e não para com o eventual espaço para a conquista do consumidor. $E$ mais, medicamentos ou cosméticos, em razão da relação com a saúde e com a vida, não devem ser expostos no mercado como atrativo, mas sim como alternativa a questões específicas.

A questão da divulgação é tão séria para a saúde e para a vida que o assunto é regulado pela ANVISA por meio da Resolução n. 102, de 30 de novembro de 2000, a qual limita a divulgação de medicamentos e cosméticos, destacadamente, dos primeiros, eis que esta espécie de produto não pode ser oferecida como "produto", mas sim como "meio" ou "alternativa" voltada ao saneamento ou mitigação de problemas de saúde.

Pelas mesmas razões, a ANVISA também regulamenta a forma de exposição desses produtos nos estabelecimentos específicos - que são as drogarias/farmácias - por meio da Resolução da Diretoria Colegiada n. 44/ 2009. Demonstrando, uma vez mais, que se deve prevalecer os interesses públicos, ou seja, os da saúde pública. Restando muito pouco espaço de atuação para a iniciativa privada na captação de clientes, por meio do Direito Autoral.

\section{O DIREITO DAS MARCAS}

O que não se protege como Direito Autoral pode ser protegido pelo Direito das Marcas, eis que as embalagens de medicamentos e de cosméticos representam um conjunto de informação através da composição de forma, cor, expressão e imagem. O responsável pelo registro deste conjunto é o INPI, o qual classifica estas identificações como Marca nominativa (expressão), figurativa (imagem) ou mista (combinação do nominativo com o figurativo). A prática demonstra que medicamentos e cosméticos possuem valor agregado através da exteriorização do conjunto informativo (ou conjuntoimagem ou trade-dress), em que o consumidor é atraído pelo que "Ihe salta aos olhos".

José Carlos Tinoco Soares ${ }^{(1)}$, quanto ao entendimento do que seja conjunto informativo, esclarece:

Vale isto dizer que é livre o requerimento de qualquer marca, como também é por demais curial que livre será o requerimento de duas marcas, como se fora apenas uma. Esta é a marca dupla ou a marca composta de dois elementos verbais interligados ou completamente distintos, formando um conjunto.

(1) SOARES, José Carlos Tinoco. Tratado da propriedade industrial, marcas e congêneres. São Paulo: Ed. Jurídica Brasileira, 2003. v. 1, p. 219. 
A compreensão do que seja o conjunto informativo assume alta relevância por se tratar de medicamento ou cosmético, no sentido de que estes produtos, como já indicado no item anterior, oferecem muito pouco espaço para as informações obrigatórias e para os dados de natureza marcária ou que exerçam o atrativo sobre o paciente/consumidor. Por isto mesmo, a importância do conjunto, o qual pode se constituir pela reunião, estratégia, de cores, nomes, formas, ilustrações e outros elementos que se façam necessários ou relevantes.

Estas Marcas são protegidas pela Lei da Propriedade Industrial n. 9.279 de 14 de Maio de 1996:

Art. 122. São suscetíveis de registro como Marca os sinais distintivos visualmente perceptíveis, não compreendidos nas proibições legais.

Art. 123. Para os efeitos desta Lei, considera-se:

I - Marca de produto ou serviço: aquela usada para distinguir produto ou serviço de outro idêntico, semelhante ou afim, de origem diversa; (grifos do autor)

Prestam-se as Marcas para, inicialmente, identificarem um produto, a fim de que o mesmo atraia o consumidor e, em um segundo momento, para diferenciá-lo dos demais, mitigando a concorrência. Demonstra-se, assim, o potencial econômico da Marca, ainda mais quando acompanhada de um bom serviço de marketing. Serviço este que, no caso dos medicamentos e dos cosméticos, é limitado, em razão da relação direta que promovem ou podem promover sobre a saúde e a vida com dignidade.

Conforme mencionado, proibe-se o registro de Marca comum ou genérica, ao menos de modo exclusivo, permitindo-se o registro dentro de um conjunto informativo, já que estas estão inseridas no conceito de domínio público. E isto ocorre porque as Marcas devem ser diferenciadas, ou seja, deve ser aplicada a criatividade humana na composição desse sinal e não apenas socorrer-se a um sinal diluído ou difuso:

Art. 124. Não são registráveis como Marca:

(...)

VI — sinal de caráter genérico, necessário, comum, vulgar ou simplesmente descritivo, quando tiver relação com o produto ou serviço a distinguir, ou aquele empregado comumente para designar uma característica do produto ou serviço, quanto à natureza, nacionalidade, peso, valor, qualidade e época de produção ou de prestação do serviço, salvo quando revestidos de suficiente forma distintiva;

(...)

VIII - cores e suas denominações, salvo se dispostas ou combinadas de modo peculiar e distintivo; (grifos do autor) 
Busca a lei que o interessado estabeleça distinção para o uso daquilo que é comum, ou seja, que promova um diferencial na identificação do sinal quando da apresentação do medicamento ou cosmético. Caso contrário, estar-se-ia destinando exclusividade a "um" e afastando e impedindo "todos" de se utilizarem daquilo que pertence à comunidade, ou seja, que não é passível de exclusividade. O inciso VIII, do artigo 124, bem ilustra a situação com a indicação das "cores", já que estas pertencem a toda humanidade, mas dentro de uma composição distinta, integrando um conjunto informativo, poderá destinar-se ao interessado que promova a referida distintibilidade. É o caso também do inciso II, do mesmo dispositivo legal, ao referir-se aos "algarismos" que são de titularidade do "todo", já que expressões de um comum, genéricas, de domínio público.

O artigo 124 da Lei da Propriedade Industrial incentiva a indústria a ser criativa na eleição e composição de sua Marca, mas também protege o consumidor frente a marcas que sejam muito semelhantes, ao ponto de poderem causar confusão na escolha do consumidor. Desta feita, proibe-se o registro de algumas formas de exteriorização. Esta permanente preocupação da ordem jurídica faz-se presente, especificamente, neste mercado, em virtude da relevância que assume a temática aos interesses públicos, com maior ênfase à saúde pública. Desta forma, a iniciativa privada sabe, desde a origem de suas atividades, que o seu Direito sobre a Propriedade de um bem intelectual é limitada.

Ainda assim, reconhece-se que existe uma tendência de mercado representada por uma mínima identificação em categorias específicas, por exemplo, guardam semelhanças, quanto à forma, as embalagens de anticoncepcionais, de homeopáticos, de cremes faciais e de protetores solares. Em outras situações, quanto à expressão utilizada como identificadora, produtos que se apresentam através do próprio ativo químico e utilização de sufixos e prefixos. Contudo, esta semelhança não pode ser o suficiente para provocar confusão e, automaticamente, desvio de clientela em razão da identificação ou contrafação.

As semelhanças, dentro da admitida tendência de mercado, afastadas, portanto, da identificação ou contrafação, justificam-se, também, em razão das informações que devem, obrigatoriamente, constar das respectivas embalagens. Por isto mesmo, a indústria, dentro da criação do espírito, desenvolveu a concepção de conjunto-imagem (trade-dress), o qual oferece o produto com forma, cor, informação e imagem, de modo combinado e, por vezes, de modo tridimensional, buscando a proteção/titularidade sobre o todo e não sobre cada elemento, a não ser quando a lei o permita (normalmente não se inserindo no conceito de comum, genérico ou domínio público).

Equivale o trade-dress ao conjunto informativo, ou seja, ao todo da apresentação do produto, através dos elementos nominativos e figurativos. Em que a titularidade, junto ao INPI, adquire-se com exclusividade sobre o 
conjunto, diante mesmo, em algumas situações, de impossibilidade do registro de Marca sobre o elemento individualizado, como as "cores". Na prática, registra-se e usa-se o conjunto, não podendo fazer o mesmo para com o sinal individual.

O Poder Judiciário brasileiro, de modo geral, entende pela defesa do tradedress, eis que, desta forma, protege o titular com a distinção e o consumidor com a capacidade de escolha, através do efetivo Direito sobre a Informação:

\section{EMENTA}

"ABSTENÇÃO DE USO DE MARCA - TRADE DRESS SEMELHANÇA ENTRE EMBALAGENS DOS PRODUTOS QUE PODE ACARRETAR CONFUSÃO AO CONSUMIDOR. Sentença de procedência - Apelo da ré - Semelhança entre as embalagens dos produtos da autora e da ré corretamente reconhecida. Possibilidade de confusão ao consumidor que autoriza a proteção do conjunto-imagem - Desnecessidade de registro - Proteção contra concorrência desleal prevista no artigo $2^{\circ}$,, $\mathrm{V}$, da Lei de Propriedade Industrial - Sentença mantida - Recurso improvido."(TJ/SP, Rec. Ap. 3749514800, 9a Câmara de Direito Privado, Des. Rel. Graciella Salzman, julg. 23/10/2009) (grifos do autor)

Esta respeitabilidade imposta pela legislação o é deste modo para afastar, conforme mencionado, a identificação, a reprodução, a contratação praticada por terceiros que busquem usurpar do patrimônio alheio, desviando-Ihe a clientela e locupletando-se ilicitamente. Situações estas que afetam negativamente a esfera do paciente/consumidor, certo é que este pode estar sujeito a produtos falsificados.

\section{O DIREITO DO DESENHO INDUSTRIAL}

Pode o Desenho Industrial ser considerado como complemento do conjunto informativo, eis que um não anda sem o outro, principalmente, ao se considerar a embalagem, o invólucro do medicamento e do cosmético.

O Desenho Industrial também é disciplinado pela Lei da Propriedade Industrial, a qual em seu artigo 94 oferece a possibilidade de registro:

Artigo 94. Ao autor será assegurado o direito de obter registro de desenho industrial que Ihe confira a propriedade, nas condições estabelecidas nesta Lei.

Art. 95. Considera-se desenho industrial a forma plástica ornamental de um objeto ou o conjunto ornamental de linhas e cores que possa ser aplicado a um produto, proporcionando resultado visual novo e original na sua configuração externa e que possa servir de tipo de fabricação industrial. (grifos do autor) 
Configura-se como a forma plástica ornamental de um objeto ou o conjunto ornamental de linhas e cores que possa ser aplicado a um produto, proporcionando resultado visual novo e original na sua configuração externa e que possa servir de fabricação industrial. Desde, é claro, repita-se, que não guarde a mínima possibilidade de confundir o consumidor, por se tratar de interesse público a clareza da informação e mesmo da apresentação.

Até mesmo a forma plástica guarda relação com a saúde pública, uma vez que as embalagens de medicamentos e cosméticos não devem ser um "atrativo", por exemplo, às crianças. A ideia do legislador é de que o paciente, em que pese ser consumidor no ato da aquisição, não deve ser tratado como consumidor na concepção da palavra. A forma plástica presta-se mais a informar do que a angariar o consumo do produto pelo atrativo estético. Tanto é verdade que, no Brasil, medicamentos são comercializados apenas em drogarias e sob a égide de regramentos sobre a exposição dos mesmos.

Do mesmo modo que o Direito das Marcas, o Desenho Industrial deve ser novo, ou seja, não corresponder ao estado da técnica e possuir uma configuração visualmente distinta em comparação aos demais objetos. Corresponde à forma pela qual se revestem os produtos aqui sob análise.

\section{O DIREITO SOBRE PATENTE INDUSTRIAL LIMITADO À ACESSIBILIDADE DE MEDICAMENTO}

A tutela, até então exposta, é perceptível aos olhos do homem de inteligência mediana. Porém, resta a proteção, pelo INPI, via a concessão de Patente Industrial sobre a formulação do medicamento ou do cosmético. Em que esta não se oferece aos "olhos" do consumidor ou profissional especializado, apenas a sua composição básica, uma vez que se trata de segredo industrial, em conformidade com a mesma Lei da Propriedade Industrial:

Art. 6 Ao autor de invenção ou modelo de utilidade será assegurado o direito de obter a Patente que Ihe garanta a propriedade, nas condições estabelecidas nesta Lei.

Art. 8 É Patenteável a invenção que atenda aos requisitos de novidade, atividade inventiva e aplicação industrial.

Art. 11. A invenção e o modelo de utilidade são considerados novos quando não compreendidos no estado da técnica.

Art. 13. A invenção é dotada de atividade inventiva sempre que, para um técnico no assunto, não decorra de maneira evidente ou óbvia do estado da técnica.

Art. 15. A invenção e o modelo de utilidade são considerados suscetíveis de aplicação industrial quando possam ser utilizados ou produzidos em qualquer tipo de indústria. (grifos do autor) 
A formulação que produz um medicamento ou um cosmético deve ser nova, consequência de atividade inventiva e ter aplicação industrial. Ninguém pode ser titular daquilo que já existe na natureza ou no estado natural, e somente foi descoberto, exemplo a formologia de uma planta ou o sequenciamento de DNA do ser humano. A atividade inventiva complementa a novidade, já que exige a contribuição do homem na realização da invenção, distanciando-se, uma vez mais, da descoberta. E a aplicação industrial corresponde à possibilidade, não sendo obrigatória aplicação imediata como condicionante da concessão da Patente Industrial.

Em sendo atendidos os critérios de patenteabilidade, de modo cumulativo e não alternativo, o interessado usufruirá da titularidade exclusiva, no Brasil, pelo período de vinte anos.

Ocorre, conforme já mencionado, que o Direito sobre a Propriedade Intelectual nasce limitado; o interessado a qualquer destes direitos sabe que, além de atender a requisitos legais para a obtenção do Direito, ainda assim, sofrerá limitações no exercício da titularidade exclusiva. Por exemplo, o período desta exclusividade, a qual varia, a depender do país e da espécie da Propriedade Intelectual a que se refere, de 10, 15 ou 20 anos, ou em vida, e mais 70 anos para os herdeiros em caso de Direito Autoral.

A limitação se justifica porque a Propriedade, desde os trabalhos iniciais da Organização das Nações Unidas, é considerada um direito sui generis, pois envolve, concomitantemente, interesse público e privado. O primeiro relacionado às acessibilidades (saúde, vida, dignidade, informação, cultura e desenvolvimento) voltadas ao exercício do interesse público; o segundo, relacionado aos interesses da iniciativa privada (titularidade, livre iniciativa, livre concorrência, lucro e desenvolvimento) voltada ao exercício sobre a propriedade.

Assim, ainda hoje, a problemática é permanente: como harmonizar, diante da imperiosa necessidade, os interesses público e privado quando relacionados ao Direito da Propriedade Intelectual? Relacionando a questão com a presente temática: como harmonizar o Direito à Saúde com o Direito da Propriedade? Como relacionar o Direito à Informação com o Direito ao Segredo Industrial? Em suma, como promover acessibilidade a medicamento (os cosméticos se afastam da discussão) e manter a proteção ao titular da pesquisa e/ou do produto?

A resposta às indagações é a mesma: a limitação legal. Todos os direitos da Propriedade Intelectual nascem limitados: primeiro o atendimento aos requisitos legais para a concessão das espécies da Propriedade Intelectual; segundo pela limitação dos prazos de titularidade exclusiva, já que não é ad perpetum; e, terceiro, pelo predomínio do interesse público que pode, inclusive, suspender os direitos da Propriedade Intelectual. É sobre este que se debruçam os argumentos seguintes. 
O Direito à Saúde envolve o bem-estar físico e psíquico, e todas as aplicações que mitiguem ou restabeleçam a saúde, tendo por parâmetro a vida com dignidade e a obediência aos parâmetros legais de cada país, destacadamente, em legislação sanitária. O conceito é progressivo, ou seja, toda e qualquer nova aplicação insere-se na concepção do Direito a ser fornecido (trata-se de um Direito enumerativo e não taxativo), assim como na concepção da obrigação estatal. É neste momento que surgem os medicamentos como elemento do Direito à Saúde, sendo, portanto, direito de todos e dever do Estado - artigo 6o da Constituição Federal:

Art. 6o São direitos sociais a educação, a saúde, o trabalho, a moradia, o lazer, a segurança, a previdência social, a proteção à maternidade e à infância, a assistência aos desamparados, na forma desta Constituição. (grifos do autor)

Diversos conceitos são oferecidos à saúde, de ordem internacional, nacional, constitucional, infraconstitucional, social e econômica. Todavia, a Organização Mundial do Comércio, que é qualificada ao comércio internacional, reconhecendo a importância da harmonização desses direitos, estabelece que saúde é:

$\mathrm{O}$ acesso a medicamentos essenciais e as vacinas dependem de quatro fatores críticos: preços acessíveis, seleção e uso racional dos sistemas de financiamento. Em que pesem os últimos três elementos, são igualmente importantes para enfocar o problema do acesso a medicamentos na perspectiva correta, quando se trata da relação entre saúde e comércio, a atenção se concentra nos preços dos medicamentos. (2)

Medicamentos são componentes do Direito à Saúde, assim como atendimento hospitalar, atendimento médico, realização de exames e acompanhamentos. O seu fornecimento cabe ao Estado, que deve produzilo, adquiri-lo ou estabelecer parcerias (Joint Venture) que possibilitem uma ou outra situação. Devem, também, em nome, uma vez mais, da saúde pública, os medicamentos serem avaliados pela ANVISA, como forma de assegurar o bem-estar da sociedade sobre os resultados e contraindicações do mesmo. A política de fornecimento de medicamentos deve ser preventiva, no sentido de que o Estado deve se programar dentro de um critério temporal, de necessidade e de orçamento. Esta, ao menos, é a situação ideal.

Em que pesem as diretrizes, que no Brasil são constitucionais, a realidade é que o fornecimento de medicamentos, sejam eles essenciais ou não, dependem primordialmente da iniciativa privada. E esta, em razão da livre iniciativa, pesquisa, desenvolve e comercializa o que the for mais

(2) OMC. Los Acuerdos de la OMC y la Salud Públic: un estudio conjunto de la OMS y la Secretaria de la OMC. Genebra: OMC, 2002. p. 97. 
lucrativo. Reconhecendo esta infeliz e "permanente" situação, os países estabeleceram a possibilidade de suspensão dos direitos da Propriedade Intelectual sobre medicamentos, em razão do interesse ou necessidade pública, através do licenciamento compulsório.

O licenciamento compulsório corresponde à suspensão temporária dos direitos sobre a patente farmacêutica, contudo, de acordo com o objetivo desta elaboração, o uso desta medida deve ser feito na correta e responsável medida, eis que a proteção dos direitos da Propriedade Intelectual colaboram, sobremaneira, para a acessibilidade. Automaticamente, a sua suspensão, ou seja, o seu afastamento, ainda que temporário, reduz a acessibilidade. Isto porque há a dependência do Estado para com a iniciativa privada na pesquisa, desenvolvimento e comercialização de medicamentos. Por isto mesmo, deve o licenciamento compulsório ser utilizado como medida alternativa ao atendimento da necessidade pública, em conformidade com a Lei da Propriedade Industrial:

Art. 68. O titular ficará sujeito a ter a patente licenciada compulsoriamente se exercer os direitos dela decorrentes de forma abusiva, ou por meio dela praticar abuso de poder econômico, comprovado nos termos da lei, por decisão administrativa ou judicial.

Neste sentido, observa-se que o Estado, ao determinar o licenciamento compulsório, deve ter a justa medida das repercussões na esfera econômica e social, o critério temporal e a capacidade orçamentária. Tudo isto porque o licenciamento é temporário e deve durar o tempo suficiente para o restabelecimento da saúde pública que depende do referido medicamento. Ou seja, a iniciativa privada não se substitui ao Estado, este não pode utilizar-se, arbitrariamente, da propriedade alheia para sanar ausência ou insuficiente capacidade política, orçamentária e de gestão.

Importante também compreender que saúde pública é elemento do interesse público, todavia, é necessária a compreensão de que, para fins de licença compulsória, o interesse público volta-se para uma situação sui generis, ou seja, "anormal", "diferenciada" em matéria de saúde coletiva. A problemática não pode corresponder a uma situação rotineira, mas sim de exceção, por exemplo, um surto. Se assim não o for, estar-se-ia admitindo que a iniciativa privada respondesse pela irresponsabilidade, incapacidade e inconstitucionalidade do Estado frente à obrigatória atuação preventiva, dentro de um justo critério temporário e orçamentário.

Nestes termos, reconhecendo a urgência de medidas eficazes, sugere-se que os países, destacadamente os em desenvolvimento e os de menor desenvolvimento relativo, estabeleçam joint ventures com a iniciativa privada, assim como ocorre nos Estados Unidos, para a pesquisa, desenvolvimento e comercialização de produtos fármacos. Sempre com a salvaguarda da efetiva transferência de tecnologia também para o Estado. 


\section{O DIREITO DE SOFTWARE}

Em virtude da complexidade que envolve a pesquisa e o desenvolvimento de medicamentos e cosméticos, por certo que estas atividades contam na atualidade com o apoio de sistemas computadorizados, de meios eletrônicos, os quais reduzem o lapso temporal e permitem maior eficácia na obtenção do resultado. Não se pode duvidar, portanto, que a indústria farmacêutica e cosmiátrica também possa proteger os Softwares de sua criação/ desenvolvimento. Os quais, aliás, não correspondem à atividade fim, todavia, compõem a "linha de produção" como elemento necessário e essencial.

Esta sistemática é protegida pela Lei n. 9.609, de 19 de Fevereiro de 1998 , que protege a propriedade intelectual de programa de computador, o qual corresponde à expressão de um conjunto organizado de instruções em linguagem natural ou codificada, contida em suporte físico de qualquer natureza, de emprego necessário em máquinas automáticas de tratamento da informação, dispositivos, instrumentos ou equipamentos periféricos, baseados em técnica digital ou análoga, para fazê-los funcionar de modo e para fins determinados.

Desta feita, ainda que de modo indireto, como parte do processo de pesquisa e ou desenvolvimento, os Softwares desenvolvidos pela própria empresa ou contratados por ela, também merecem proteção para preservar a titularidade exclusiva, salvo disposição em contrário estabelecida em contrato pelas partes envolvidas, no caso, por exemplo, de serviço terceirizado.

\section{A LIVRE CONCORRÊNCIA}

O desrespeito a qualquer dessas tutelas legais depreende a afronta à livre concorrência, já que permite a confusão e o desvio da clientela. Faz-se a afirmativa sobre a confusão, eis que a simples possibilidade acarreta o desrespeito, não é necessária a prova da efetiva confusão, com base mesmo no Código de Defesa do Consumidor. Concomitantemente, possibilita-se o desvio de clientela ou a concepção, para o consumidor, de que um medicamento ou um cosmético façam parte da linha de produção da mesma empresa. Maior ofensa ocorre quando o concorrente aproveita-se da boa reputação de outrem, fazendo com que o consumidor adquira o seu produto achando que se refere ao produto com fama, boa reputação de mercado e/ ou tempo de mercado.

Esta temática encontra-se protegida pelo artigo 10, bis, da Convenção de Paris, pelo inciso III do artigo 195 da Lei da Propriedade Industrial, pelo inciso IV do artigo 170 da Constituição Federal e pelo inciso VI do artigo 4응 do Código de Defesa do Consumidor: 
Artigo 10-bis

1) Os países da União obrigam-se a assegurar aos nacionais dos países da União proteção efetiva contra a concorrência desleal.

2) Constitui ato de concorrência desleal qualquer ato de concorrência contrário aos usos honestos em matéria industrial ou comercial.

3) Deverão proibir-se particularmente:

$1^{\circ}$ - Todos os atos suscetíveis de, por qualquer meio, estabelecer confusão com o estabelecimento, os produtos ou a atividade industrial ou comercial de um concorrente. (grifos do autor)

A Livre Concorrência, portanto, equivale à produção e comercialização de produtos dentro das condicionantes legais e na liberdade do que a lei não proibe. Esta sistemática é necessária porque a sua respeitabilidade beneficia a liberdade do titular de uma Marca e ou de uma Patente, assegurando a este que estará a salvo de arbitrariedades; mas também o seu concorrente, eis que a prática da atividade nos contornos legais assegura a esse que a liberdade de todos produzirem e comercializarem ver-se-à respeitada. É por isto que a Convenção de Paris usa das expressões "uso honesto" e "confusão".

Dentro da hierarquia do sistema constitucional brasileiro, tem-se a Livre Iniciativa, diretamente vinculada à Livre Concorrência:

Art. 170. A ordem econômica, fundada na valorização do trabalho humano e na livre iniciativa, tem por fim assegurar a todos existência digna, conforme os ditames da justiça social, observados os seguintes princípios:

(...)

IV — livre concorrência;

Coibir atos de abuso à Livre Iniciativa faz-se necessário para a harmonia do sistema econômico e também social, já que a iniciativa privada precisa ser motivada à pesquisa, ao desenvolvimento e à comercialização de medicamentos, inclusive os essenciais. O Estado, ao deixar de proteger, desmotiva a iniciativa privada na realização de pesquisa, desenvolvimento e produção na esfera industrial. E setores existem que são essenciais como o da produção de medicamentos e mesmo os de cosméticos, reportando-se novamente ao uso necessário de protetores solares. Funciona mesmo como um acordo tácito entre o Estado e a iniciativa privada: o Estado protege e concede privilêgios (registro de Marca e Patente industrial) para que o operador econômico desenvolva e comercialize produtos de origem fármaca.

Para tal, necessário que, além de conceder registro de Marca, de Desenho Industrial e de Software, de conceder Patente Industrial e proteger a Livre Concorrência, necessário também que o Estado repreenda não apenas na área cível, mas também, criminalmente, estes atos abusivos: 
Art. 195. Comete crime de concorrência desleal quem:

(..)

III -- emprega meio fraudulento, para desviar, em proveito próprio ou alheio, clientela de outrem; (grifos do autor)

O meio fraudulento pode ser o uso de Marca, Desenho Industrial e Patente alheias, na sua totalidade ou parcialmente. E o crime se consubstancia com a prova do meio fraudulento, ou seja, com a prática do verbo "fraudar", o qual se demonstra através da emissão de notas fiscais, da apreensão e constatação do fato sobre mercadorias ou pela divulgação publicitária, dentre outras possibilidades.

Toda esta rede legislativa e administrativa também se justifica porque, ao se comercializar medicamentos e cosméticos, atinge-se diretamente o consumidor, ou seja, a economia popular. E este, no Brasil, é tutelado como elemento da ordem pública e, assim, o consumidor deve ser protegido contra atos abusivos que possam afetar sua saúde e/ou vida:

Art. 4ํㅗ A Política Nacional das Relações de Consumo tem por objetivo 0 atendimento das necessidades dos consumidores, 0 respeito à sua dignidade, saúde e segurança, a proteção de seus interesses econômicos, a melhoria da sua qualidade de vida, bem como a transparência e harmonia das relações de consumo, atendidos os seguintes princípios:

(...)

VI - coibição e repressão eficientes de todos os abusos praticados no mercado de consumo, inclusive a concorrência desleal e utilização indevida de inventos e criações industriais das Marcas e nomes comerciais e signos distintivos, que possam causar prejuízos aos consumidores; (grifos do autor)

Facilmente perceptível é que, se a ordem do consumidor é afrontada, é, também, a ordem econômica e, concomitantemente, a economia nacional. Não se pode autorizar, portanto, que esta seja desrespeitada pela iniciativa privada, usurpadora, que busque locupletar-se ilicitamente por meio da usurpação da propriedade alheia (Marca e Patente). O prejuízo ao consumidor ocorre de duas frentes, uma por ser levado a adquirir produto que pense ser outro ou que produz os mesmos resultados; duas porque, em matéria de medicamentos e cosméticos, problemas em sua saúde podem ser acarretados.

A decisão da $4^{\text {a }}$ Câmara de Direito Privado do Tribunal de Justiça de São Paulo, de 18 de Junho de 2009, em Apelação Cível sob n. 4018474300, em que figurou como Des. Rel. Natan Zelinschi de Arruda, observa a concorrência desleal como consequência da usurpação de Marca ou Patente de terceiro: 


\section{EMENTA}

"Propriedade industrial. Devido processo legal observado. Feito apto ao julgamento no estado. Embalagens similares. Produtos da mesma classe. Invólucro apresentado pela autora está compatível com a nomenclatura da mercadoria. Frasco do produto da ré não está vinculado ao nome do conteúdo, além do que, apresenta cores e figura que coincidem com o nome do produto do polo ativo. Confusão ao consumidor está caracterizada. Concorrência desleal se faz presente. Marca tem por aspecto teleológico proporcionar as distinções, ou seja, dar destaque à mercadoria do titular, e não extravasar similitude com produto e embalagem já existentes. Apelo desprovido." (grifos do autor)

Frize-se que o critério balizador é a existência ou não de distinção por parte do consumidor de percepção mediana (não se pode exigir a análise como se técnico ou especialista fosse) sobre a possibilidade de provocar confusão no mesmo. Sobre este aspecto, decisão da 7ª Câmara de Direito Privado do Tribunal de Justiça de São Paulo, em Apelação Cível sob n. 2527564800, de 25 de Junho de 2008:

\section{EMENTA}

"Obrigação de fazer cumulada com indenização. Julgamento antecipado da lide apto a sobressair, sobretudo porque fora pleiteado pela apelante anteriormente. Prova técnica observou o devido processo legal, tanto que não ocorrera nenhuma impugnação no momento da nomeação dos peritos. Marcas notórias nos produtos das partes, ou seja, Nescau e Toddy. Embalagens dos produtos levam em consideração o conteúdo, isto é, o marrom representa o chocolate, o leite simboliza o branco e o azul e o vermelho são componentes dos rótulos. Perícia apresentou as peculiaridades que distinguem ambos os rótulos, bem como o sabor dos produtos. Apelante não tem exclusividade na utilização das cores. Ambos os produtos estão há mais de meio século no mercado, por conseguinte, a população está apta a distingui-los, não podendo ser subestimada sua capacidade de escolha. Concorrência desleal não caracterizada. Livre mercado é salutar para o consumidor. Apelo desprovido." (grifos do autor)

Infelizmente, na ocorrência de uma problemática econômica ou de ordem social, como acesso a medicamentos, a responsabilidade ou a mitigação dos problemas a assuntos estatais volta-se para a iniciativa privada, ao menos esta é a prática usual. Ocorre que, salvo situações em contrário, para a pesquisa, desenvolvimento e comercialização de medicamentos e cosméticos, depende o Estado e a comunidade de um modo geral, da iniciativa privada. Esta é a detentora do orçamento, da capacidade técnica e do benefício temporal a seu favor, em razão mesmo dos altos investimentos financeiros e de pessoal. 
Desta feita, para a necessária e efetiva harmonia entre os interesses da esfera pública e privada, melhor opção é respeitar os Direitos da Propriedade Intelectual sobre os medicamentos e os cosméticos (Autoral, Marcas, Desenho Industrial, Patentes, Softwares e Livre Concorrência).

\section{CONSIDERAÇÕES FINAIS}

O Direito da Propriedade Intelectual merece respeito, não apenas em razão da tutela internacional e nacional existente, mas, destacadamente, em razão de contribuir para a acessibilidade da saúde e da vida com dignidade. Isto porque, corresponde este Direito à indústria da vida.

Indústria da vida exercida pela iniciativa privada, a qual precisa de motivação para permanecer na pesquisa, desenvolvimento, produção e comercialização de medicamentos e de cosméticos. Enfatizando-se aqueles que são de maior relevância ao Estado, ainda que não possua apelo econômico aos industriais. Motiva-se através do respeito da ordem jurídica nacional estabelecida e por meio de incentivos para as atividades afins.

No Brasil, por exemplo, das aquisições de medicamentos realizadas pelo Ministério da Saúde, 62\% (sessenta e dois por cento) são provenientes de licitações internacionais, 37\% (trinta e sete por cento) são licitações nacionais e menos de 1\% (um por cento) é adquirido por compra direta (sem licitação). É importante salientar que uma parcela de $28 \%$ (vinte e oito por cento) do custo total das licitações nacionais refere-se a medicamentos adquiridos da rede de laboratórios oficiais produtores, que fornecem medicamentos por meio de convênios e contratos, por dispensa de licitação, de acordo com a lei de licitações vigente no país; isto ocorre porque o acesso a medicamentos corresponde à exceção ao processo de licitação. Dessa forma, os Estados devem adotar, em nível nacional, todas as medidas necessárias para a realização do direito ao desenvolvimento e devem assegurar, inter alia, igualdade de oportunidades para todos no acesso aos recursos básicos, como saúde, por meio do acesso a medicamentos, e propriedade, através do direito às patentes farmacêuticas. ${ }^{(3)}$

Por outro lado, já que a acessibilidade à saúde, através de medicamentos, é função estatal, tem-se por obrigatória a busca dos países por alternativas, dentre elas, as parcerias entre os interesses públicos e privados (Joint Ventures) e o uso, de uma vez por todas, das flexibilidades, a exemplo da licença compulsória, para os casos em que esta seja devida nos termos legais.

(3) CARVALHO, Patrícia Luciane de. Patentes farmacêuticas e acesso a medicamentos. São Paulo: Atlas, 2007. p. 135. 


\section{REFERÊNCIAS BIBLIOGRÁFICAS}

CARVALHO, Patrícia Luciane de. Patentes farmacêuticas e acesso a medicamentos. São Paulo: Atlas, 2007.

OMC. Los Acuerdos de la OMC y la Salud Públic: un estudio conjunto de la OMS y la Secretaria de la OMC. Genebra: OMC, 2002.

SOARES, José Carlos Tinoco. Tratado da propriedade industrial, marcas e congêneres. São Paulo: Ed. Jurídica Brasileira, 2003. v. 1. 